\title{
Temperature and pH Responsive Microfibers for Controllable and Variable Ibuprofen Delivery
}

\author{
Toan Tran, Mariana Hernandez, Dhruvil Patel, and Ji Wu \\ Department of Chemistry, Georgia Southern University, 250 Forest Drive, Statesboro, GA 30460, USA \\ Correspondence should be addressed to Ji Wu; jwu@georgiasouthern.edu
}

Received 3 December 2014; Accepted 10 January 2015

Academic Editor: Luigi Nicolais

Copyright ( $) 2015$ Toan Tran et al. This is an open access article distributed under the Creative Commons Attribution License, which permits unrestricted use, distribution, and reproduction in any medium, provided the original work is properly cited.

\begin{abstract}
Electrospun microfibers (MFs) composed of $\mathrm{pH}$ and temperature responsive polymers can be used for controllable and variable delivery of ibuprofen. First, electrospinning technique was employed to prepare poly( $\varepsilon$-caprolactone) (PCL) and poly(Nisopropylacrylamide-co-methacrylic acid) (pNIPAM-co-MAA) MFs containing ibuprofen. It was found that drug release rates from PCL MFs cannot be significantly varied by either temperature $\left(22-40^{\circ} \mathrm{C}\right)$ or $\mathrm{pH}$ values (1.7-7.4). In contrast, the ibuprofen (IP) diffusion rates from pNIPAM-co-MAA MFs were very sensitive to changes in both temperature and $\mathrm{pH}$. The IP release from pNIPAM-co-MAA MFs was highly linear and controllable when the temperature was above the lower critical solution temperature (LCST) of pNIPAM-co-MAA $\left(33^{\circ} \mathrm{C}\right)$ and the $\mathrm{pH}$ was lower than the $\mathrm{p} K_{a}$ of carboxylic acids $(\mathrm{pH} 2)$. At room temperature, however, the release rate was dramatically increased by nearly ten times compared to that at higher temperature and lower $\mathrm{pH}$. Such a unique and controllable drug delivery system could be naturally envisioned to find many practical applications in biomedical and pharmaceutical sciences such as programmable transdermal drug delivery.
\end{abstract}

\section{Introduction}

Controllable and programmable drug delivery systems have found many applications in medical and pharmaceutical sciences $[1,2]$. Controlled drug delivery systems have been successfully applied to cancer treatments and tissue engineering with a better improved efficacy [3-5]. However, there are still two major challenges to overcome (1) reducing initial burst effects and (2) realizing a programmable drug delivery $[6,7]$. In the past decade, multiple technologies have been proposed and developed, purposing to solve or partially relieve the above-mentioned challenges [7-12]. For example, electrospinning technology is deemed as one of those most facile and low-cost methods to produce nano- and micromaterials with many novel functionalities. Drug delivery rates from these electrospun fibers can be manipulated by controlling the diameter, materials, structures, compositions, and so forth [5]. The relative large specific surface area of these materials can also benefit an enhanced solubility for most hydrophobic potent drugs. In addition, various coaxial electrospinning techniques have been adopted to realize a controllable protein delivery with minimum burst effect (protein-core and cellulose acetate shell) [13-15].

Poly(N-isopropylacrylamide-co-methacrylic acid) (PNIPAM-co-MAA) is an interesting polymer that is responsive to both $\mathrm{pH}$ and temperature changes. This type of polymers is biocompatible and has been explored widely in drug delivery and tissue engineering [16-18]. When heated above its lower critical solution temperature (LCST), the polymer undergoes a reversible phase transition from hydrophilic to hydrophobic, leading to the change of drug release rates [19]. In addition, when the $\mathrm{pH}$ is below the $\mathrm{p} K_{a}$ of carboxylic acid (such as $\mathrm{pH} 2$ ), the polymer becomes more hydrophobic due to the protonation of carboxyl groups [20]. Although PNIPAM has been fabricated into various particle formulations for drug delivery, very few studies have been reported using PNIPAM-co-MAA microfibers as drug delivery vehicles. $\mathrm{p}$ (NIPAAm-co-PAA) microgel was used as a host material to deliver the basic fibroblast growth factor (bFGF) [21]. It was found that the release rate of bFGF was much higher at $\mathrm{pH} 7.4$ compared to $\mathrm{pH} 5$ because the carboxylic acid is deprotonated at higher $\mathrm{pH}$, thus making the polymer 
more hydrophilic. Thereby water can permeate more easily into the polymeric matrix and result in a faster diffusion rate [21]. Very recently, pNIPAAm-co-pAAm copolymer was used to mask a peptide ligand that binds a widely distributed receptor (integrin $\beta 1$ ) on the surface of silica coregold shell nanoparticles. Because gold is an efficient near infrared (NIR) absorber, NIR photons can be employed to manipulate the temperature of nanoparticles, leading to the collapse of pNIPAAm-co-pAAm copolymer mask layer and resulting in a targeting drug delivery [22]. It was reported that electrospun PNIPAM-co-MAA fibers can be employed as scaffolds for tissue engineering, demonstrating excellent cell compatibility [17]. Polyvinyl alcohol (PVA) and pNIPAM coelectrospun fibers containing levothyroxine were used for transdermal delivery by Azarbayjani et al., showing a certain degree of burst effects [23]. Noteworthy, burst effects were observed under the conditions they investigated, probably because the drug is highly hydrophilic.

In this study, we fabricated pNIPAM-co-MAA electrospun microfibers loaded with hydrophobic ibuprofen drug molecules and investigated the possibility to control the drug delivery rates and burst effects by varying $\mathrm{pH}$ values and temperatures for potential pharmaceutical applications which work has never been reported to the best of our knowledge. Electrospun poly( $\varepsilon$-caprolactone) (PCL) microfibers were also studied for comparison. It was found that controlled and variable release of ibuprofen from pNIPAM-co-MAA can be obtained by applying temperature and $\mathrm{pH}$ as stimuli, whereas the ibuprofen release rates from PCL fibers are not responsive to these stimuli at all.

\section{Materials and Methods}

2.1. Materials. PCL with an average $M_{n}$ of 45,000 and pNIPAM-co-MAA with an average $M_{n}$ of 30,000-50,000 were purchased from Sigma-Aldrich. PCL pellets were sold in $100 \mathrm{~g}$ contained in a polybottle, whose melting point ranges from 56 to $64^{\circ} \mathrm{C}$. pNIPAM-co-MAA powder with $5 \mathrm{~mol} \%$ in methacrylic acid was sold in $5 \mathrm{~g}$ hold in a glass vial, whose melting point is higher than $300^{\circ} \mathrm{C}$. The pNIPAM-co-MAA polymer has a lower critical solubility temperature (LCST) of $\sim 33^{\circ} \mathrm{C}$. Ibuprofen (IP) powder with a purity $>99.0 \%$ was obtained from ACROS Organic. Ethanol and acetone with purity higher than $99.5 \%$ were purchased from EMD Millipore. Acetonitrile used for HPLC analysis was purchased from EMD Millipore also.

2.2. Fabrication of Microfibers. Two types of microfibers (MFs) (PCL and pNIPAM-co-MAA) containing ibuprofen were fabricated using a homebuilt electrospinning setup (Figure 1(a)). The electrospinning working parameters for MFs were as follows: applied voltage was direct current (DC) $25 \mathrm{kV}$ (Spellman P/N230-30R); distance between the syringe needle (16 gauge, Air-Tite Products Co.) containing the solution and the grounding collector (aluminum foil) was $10 \mathrm{~cm}$; and pumping rate of syringe was $4 \mathrm{~mL} / \mathrm{hr}$. The syringe pump was purchased from New Era Pump Systems Inc. (NE1000). Fabrication of PCL/IP MFs: first, $50 \mathrm{mg}$ IP and $1.0 \mathrm{~g}$
PCL pellets were dissolved in $10 \mathrm{~mL}$ acetone under magnetic stirring and sonication. Then the solution was electrospun into PCL/IP MFs using a single nozzle spinneret. Noteworthy, it is very difficult to dissolve more than $10 \% \mathrm{w} / \mathrm{v}$ PCL in acetone. Although the solubility of PCL can be enhanced using more toxic organic solvents such as DMF, it would raise safety concerns when they are applied to pharmaceutical and biomedical devices because residual solvent molecules could be trapped in these MFs. Fabrication of pNIPAM-co-MAA MFs: $50 \mathrm{mg}$ IP and $1.0 \mathrm{~g}$ pNIPAM-co-MAA powders were dissolved in $5.0 \mathrm{~mL}$ ethanol under magnetic stirring. Then the solution was used to fabricate pNIPAM-co-MAA MFs using a single nozzle spinneret. A high w/v percentage was used to form pNIPAM-co-MAA microfibers due to its relatively low viscosity.

2.3. Characterization of Microfibers. As-prepared samples were characterized using a Field Emission Electron Microscopy (JEOL JSM-7600F) at Georgia Southern University for morphology examinations. Fourier transform infrared (FTIR) spectra of microfiber samples were recorded in the attenuated total reflection (ATR) mode using an IR spectrophotometer (Thermo-Nicolet AVATAR 370 FT-IR Spectrometer) in the range of 4000 to $650 \mathrm{~cm}^{-1}$ at Georgia Southern University. Micromeritics ASAP 2020 Surface Area and Porosimetry Analyzer was used to measure the surface area of MFs using the 5-point Brunauer-Emmett-Teller (BET) method with nitrogen gas adsorption.

2.4. Drug Diffusion Studies. All ibuprofen studies involving the two types of MFs were carried out using a $5 \mathrm{~mL}$ PermeGear Franz cell (Figure 1(b)) with a $10 \mathrm{~mm}$ diameter orifice for sampling. $\sim 20 \pm 1 \mathrm{mg}$ MFs were wetted and suspended in the receptor chamber containing $4.0 \mathrm{~mL}$ of $\mathrm{pH} 7.4$ distilled water or $\mathrm{pH} 1.7$ aqueous solution. The $\mathrm{pH} 1.7$ acidic solutions were prepared by dissolving $0.74 \mathrm{~g} \mathrm{KCl}$ and $1 \mathrm{~mL}$ concentrated $\mathrm{HCl}$ in $1 \mathrm{~L}$ deionized water. Magnetic stirring bar was used during the drug diffusion studies. $1 \mathrm{~mL}$ solution was pipetted from the receiver chamber per hour and stored into $1.8 \mathrm{~mL}$ amber glass vials for HPLC analysis. The chamber was back-filled with $1.0 \mathrm{~mL}$ deionized water after each sampling. All drug release profiles were averaged from triple measurements.

2.5. HPLC Measurements and Data Analysis. All ibuprofen samples were analyzed by a Shimadzu LCAT High Performance Liquid Chromatography (HPLC) consisting of SIL20AHT autosampler, LC-20AT HPLC pump, and SPD-20A dual UV/Vis absorbance detector set at a wavelength of $254 \mathrm{~nm}$ and utilizing LabSolutions software. Thermo Scientific $(250 \mathrm{~mm} \times 4 \mathrm{~mm}$; $\mathrm{L} \times$ I.D. $)$ was used for the separation. The mobile phase consisted of $0.1 \mathrm{wt} \% \mathrm{H}_{3} \mathrm{PO}_{4}$ aqueous solution:acetonitrile $(55: 45)$ and flow rate of $1.0 \mathrm{~mL} / \mathrm{min}$. Calibration plots were prepared using IP standards with concentrations over a range of $20-100 \mathrm{ppm}$. The correlation coefficient $\left(r^{2}\right)$ obtained was $\geq 0.99$ for standard curves. The cumulative quantity of drug collected in the receiver compartment was plotted as a function of time. 


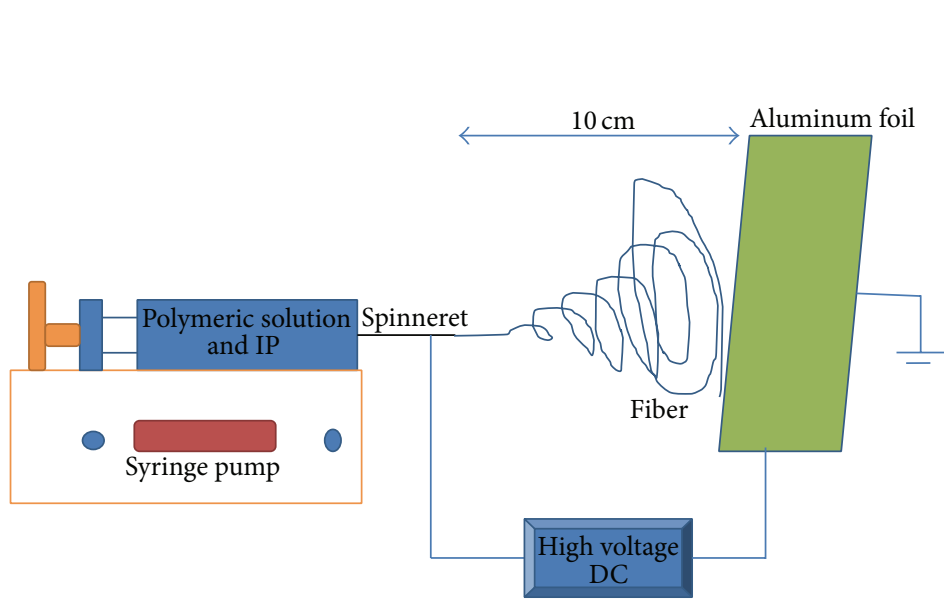

(a)

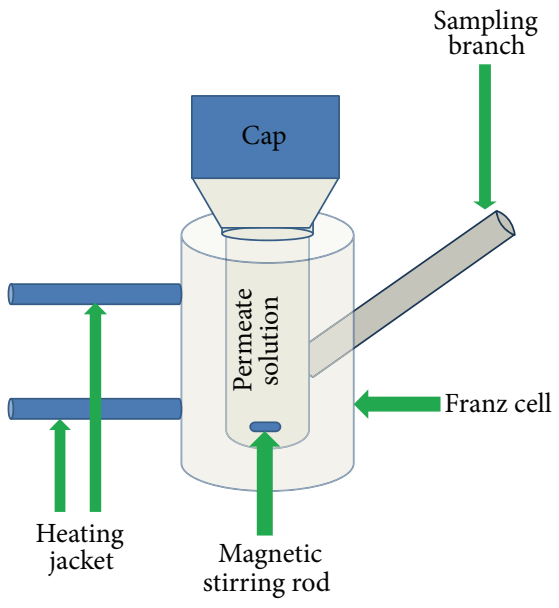

(b)

FIGURE 1: Schematic of (a) the electrospinning setup for the fabrication of PCL and PNIPAM-co-MAA MFs containing ibuprofen; (b) the Franz diffusion cell used for the drug diffusion studies.

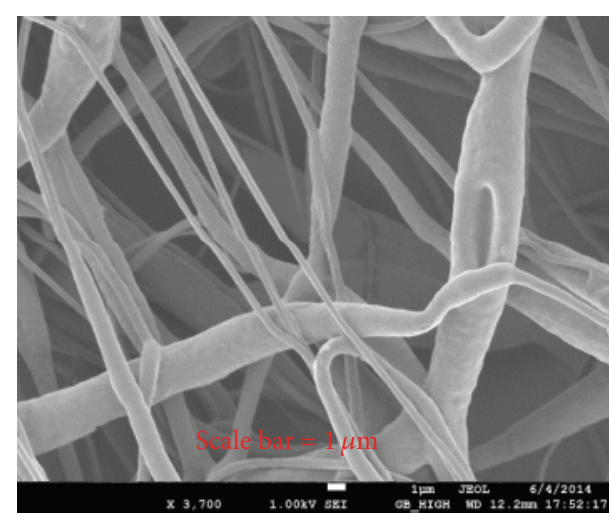

(a)

PCL/IP MFs

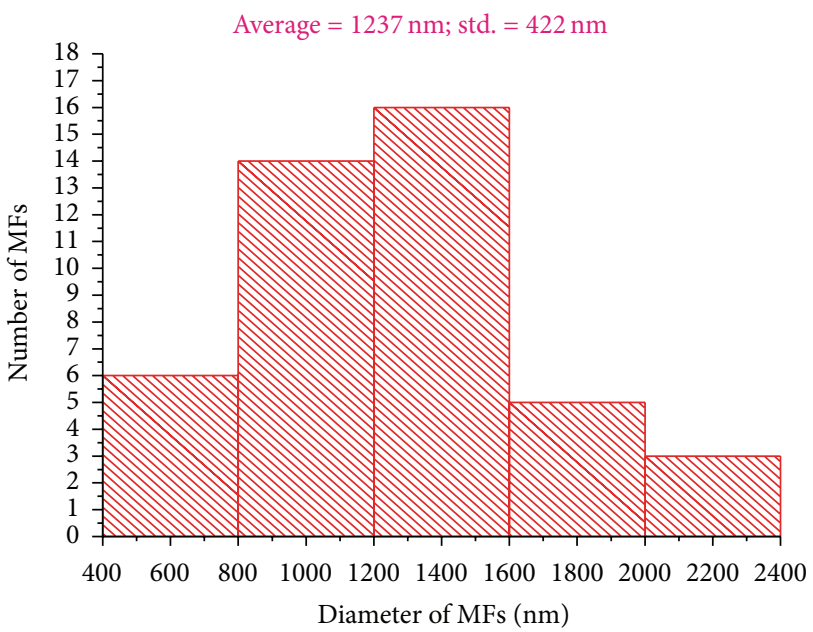

(c)

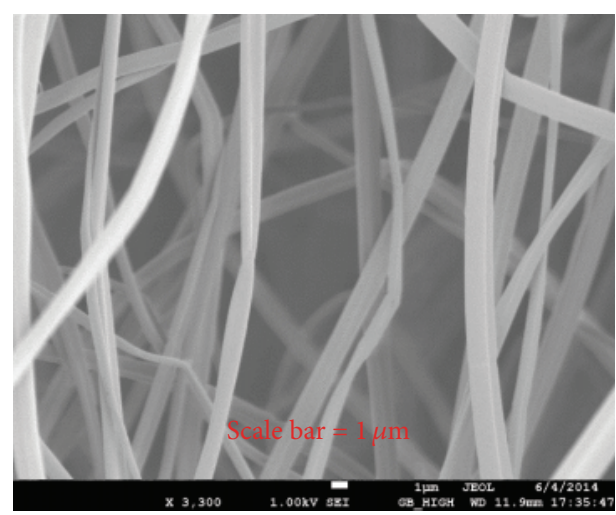

(b)

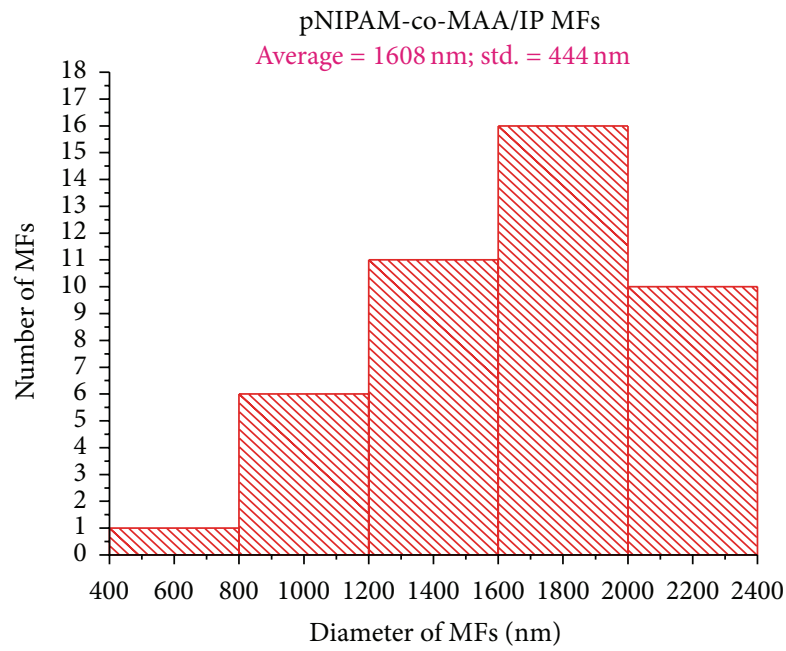

(d)

FIGURE 2: Scanning electron spectroscopy images of (a) PCL/IP MFs; (b) pNIPAM-co-MAA/IP MFs; (c) and (d) are their diameter distribution histograms, respectively. 

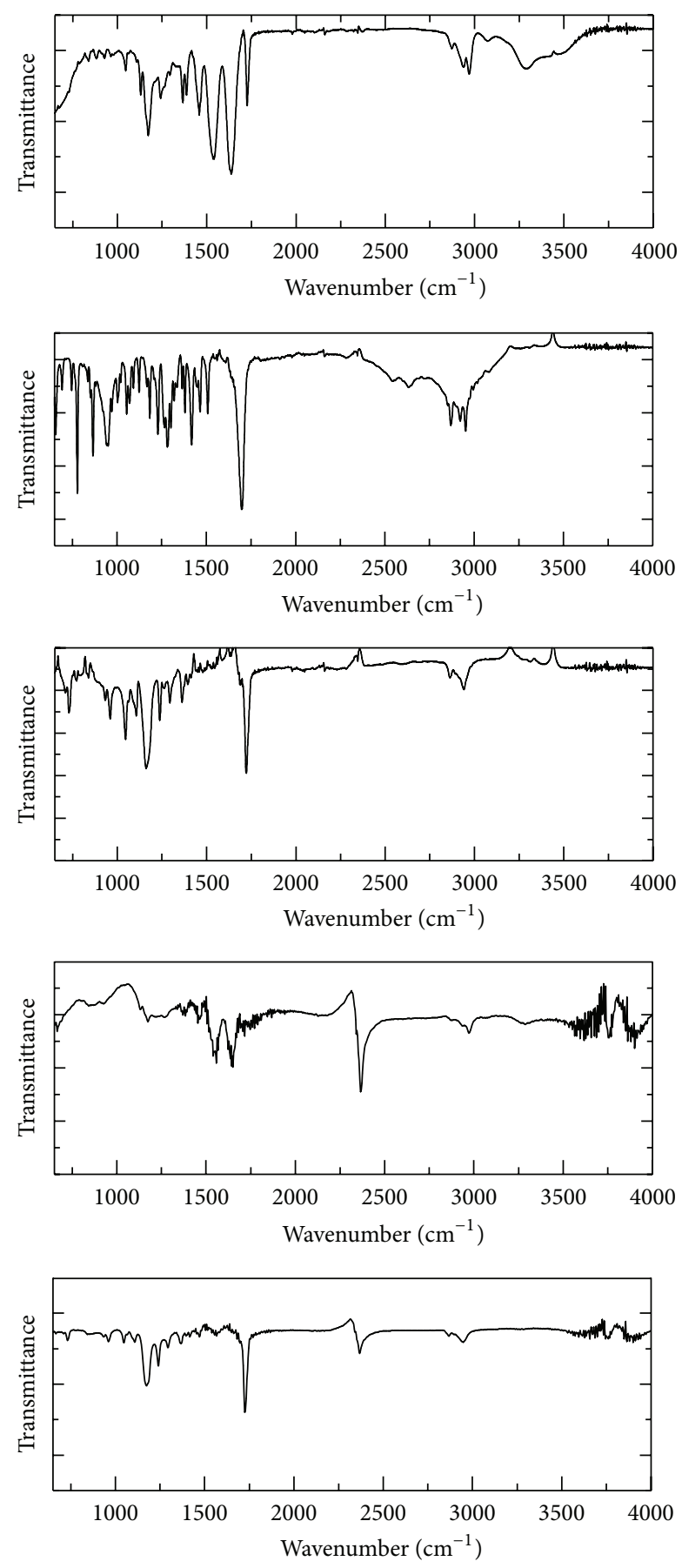

FIgURE 3: FTIR spectra of PCL/IP and pNIPAM-co-MAA/IP microfibers (MFs), as well as spectra of PCL, pNIPAM-co-MAA, and IP for comparison.

\section{Results and Discussion}

Figure 2 shows that the average diameter of PCL/IP MFs was $\sim 1237 \mathrm{~nm}$ with a large standard deviation of $422 \mathrm{~nm}$. The average diameter of bifunctional pNIPAM-co-MAA microfibers was $\sim 1608 \mathrm{~nm}$ with a standard deviation of $444 \mathrm{~nm}$ (Figure 2). Notably, there were no apparent drug particles on the surface of these MFs, which can help reduce
TABLE 1: Surface area of PCL/IP and pNIPAM-co-MAA/IP MFs.

\begin{tabular}{lcc}
\hline Sample & PCL/IP MFs & pNIPAM-co-MAA/IP MFs \\
\hline $\begin{array}{l}\text { Surface } \\
\text { area } \\
\left(\mathrm{m}^{2} \mathrm{~g}^{-1}\right)\end{array}$ & $0.974 \pm 0.036$ & $0.662 \pm 0.104$ \\
\hline
\end{tabular}

the burst effect due to the quick dissolution of these surface drug molecules. Surface area analysis shows that the specific surface area of PCL/IP and pNIPAM-co-MAA/IP MFs is 0.974 and $0.662 \mathrm{~m}^{2} \mathrm{~g}^{-1}$, respectively, which is highly consistent with their SEM data (1237 and $1608 \mathrm{~nm}$ in diameter) and literature reported value [24] (Table 1).

Fourier transform infrared (FTIR) spectroscopy (Figure 3) was utilized to characterize these MF samples. PCL fingerprint peak at $2948 \mathrm{~cm}^{-1}$ is derived from asymmetric $\mathrm{CH}_{2}$ stretching [25]. Strong peaks at $1736 \mathrm{~cm}^{-1}$ and $1176 \mathrm{~cm}^{-1}$ can be assigned to $\mathrm{C}=\mathrm{O}$ and $\mathrm{C}-\mathrm{O}$ stretching, respectively [26]. In the FTIR spectrum of pNIPAM-co-MAA/IP microfibers, characteristic peaks of pNIPAM located at 1650 and $1558 \mathrm{~cm}^{-1}$ can be assigned to amide carbonyl stretching and amide $\mathrm{N}-\mathrm{H}$ bending, respectively [27]. Carbonyl stretching from MAA carboxylic acid groups can be seen at $1716 \mathrm{~cm}^{-1}$. C-O stretching peak at $1172 \mathrm{~cm}^{-1}$ was also observed. For better comparison, FTIR spectra of pure PCL, IP, and pNIPAM-co-MAA were also shown in Figure 3. The IP peaks cannot be clearly identified due to their low weight percentage $(5 \mathrm{wt} \%)$ and the significant overlapping with other polymers (Figure 3 ).

The diffusion rates of ibuprofen from two types of MFs were investigated at 22 and $40^{\circ} \mathrm{C}$ and $\mathrm{pH} 1.7$ and 7.4 (Figure 4). It can be seen that $0.85 \mu \mathrm{mol}$ of ibuprofen was quickly released from pNIPAM-co-MAA/IP MFs in the first one hour at $22^{\circ} \mathrm{C}$ and $\mathrm{pH} \mathrm{7.4}$, and then the rest was released at a much slower rate, $0.29 \mu \mathrm{mol} \mathrm{hr}^{-1}$. Similarly, ibuprofen was released at a rate of $0.97 \mu \mathrm{molhr}{ }^{-1}$ in the first two hours at $\mathrm{pH}$ 1.7 and $22^{\circ} \mathrm{C}$, which was then followed by a slower rate of $0.54 \mu \mathrm{mol} \mathrm{hr}{ }^{-1}$. Because the LCST of pNIPAM-co-MAA is $\sim 33^{\circ} \mathrm{C}$, the polymer is quite hydrophilic at $22^{\circ} \mathrm{C}$. So water can easily permeate through the polymer matrix, resulting in a fast diffusion rate. In contrast, IP was released at a much slower rate when the temperature was increased to $40^{\circ} \mathrm{C}$. The average release rate was only $0.09 \mu \mathrm{mol} \mathrm{hr}^{-1}$ at $\mathrm{pH} 7.4$ and $40^{\circ} \mathrm{C}$. It is because pNIPAM-co-MAA became much more hydrophobic above its LCST and thus functioned like a drug depot to prohibit the fast release of hydrophobic IP molecules. This rate was $\sim 10$ times slower than that at room temperatures. In addition, the standard deviation bar is also smaller, indicating that the drug delivery is more repeatable at high temperature using pNIPAM-co-MAA as the host material. At $\mathrm{pH} 1.7$ and $40^{\circ} \mathrm{C}$, the drug release rate of IP from pNIPAM-co-MAA MFs was even slower $\left(0.05 \mu \mathrm{mol} \mathrm{hr}{ }^{-1}\right)$ and there was no burst effect. It is because when the $\mathrm{pH}$ was lower than the $\mathrm{p} K_{a}$ of carboxylic acid the carboxyl groups of the polymer were protonated, making the polymer even more hydrophobic. Thereby the hydrophobic IP release rate was further reduced and better controlled. It should be pointed 


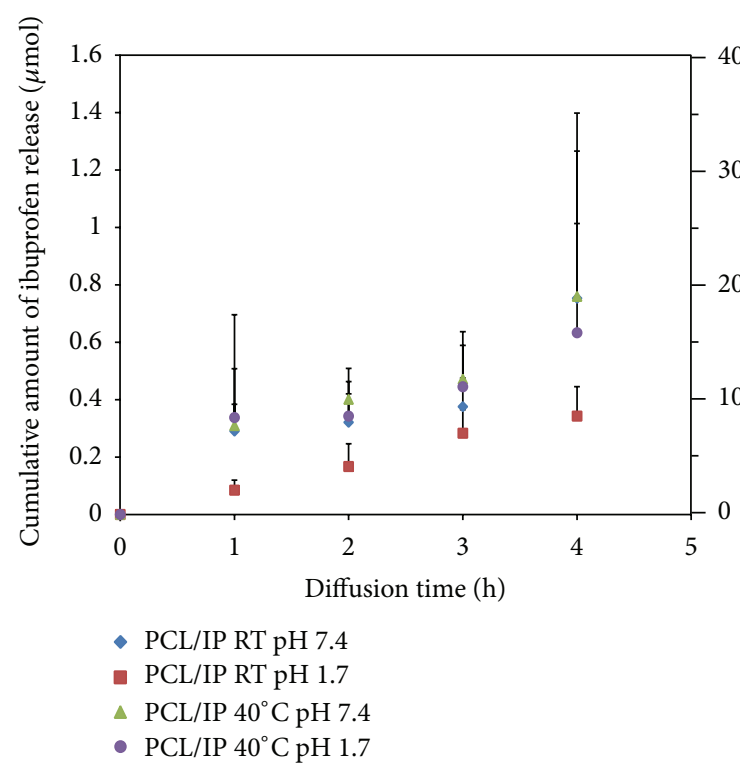

(a)
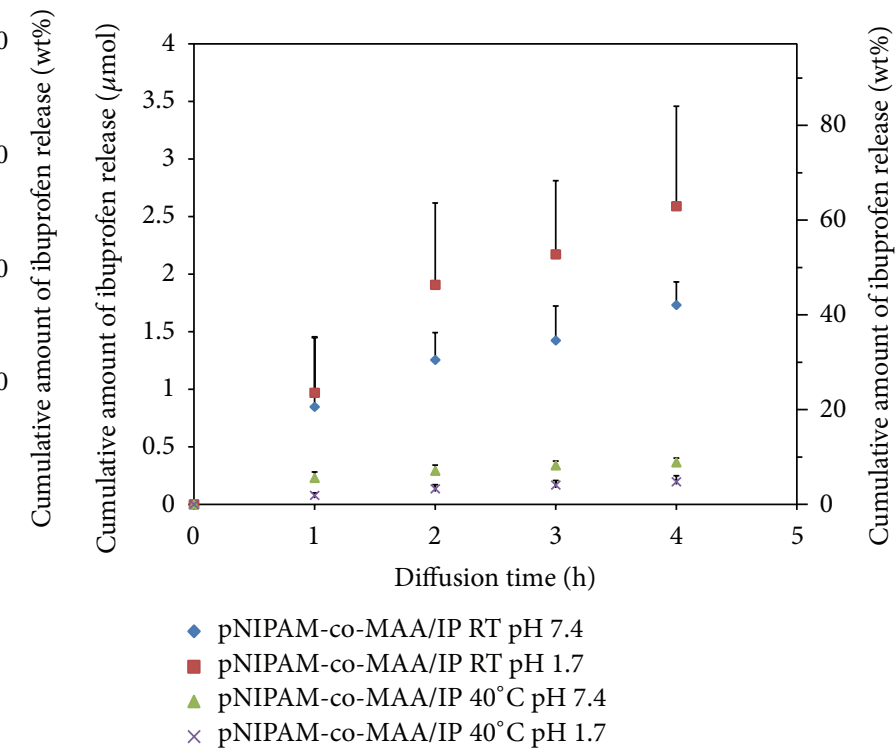

(b)

FIGURE 4: Ibuprofen release profiles from (a) PCL MFs containing $50 \mathrm{mg}$ Ibuprofen/g MFs, (b) pNIPAM-co-MAA MFs containing 50 mg Ibuprofen/g MFs. * std. bars were obtained from the measurements of triple diffusion studies. RT: room temperature $22^{\circ} \mathrm{C}$.

out that although PNIPAM-co-MAA is biodegradable in the presence of catalytic enzymes, the rate is quite slow (several percent by weight in 3 days) [28]. Our diffusion time was only 4 hours and there were no catalytic enzymes. Thereby, the effect of biodegradation on drug diffusion rates is negligible. We also believe that the release of ibuprofen is mainly from the passive diffusion through PNIPAM-co-MAA microfiber matrix. No drug particles were observed on the surface or in between the fibers under SEM imaging, indicating that ibuprofen was not released through the interconnected microfiber networks.

In dramatic contrast, the IP release from PCL/IP MFs was not sensitive to either $\mathrm{pH}$ or temperature changes (Figure 4) because PCL molecules have no functional groups that can respond to either $\mathrm{pH}$ or temperature stimuli. The average release rate of IP was $\sim 0.2 \mu \mathrm{mol} \mathrm{hr}^{-1}$ and there was a serious burst effect in the first one hour. The diffusion rate of ibuprofen from PCL MFs was slower at room temperature and $\mathrm{pH}$ 1.7. It is because the IP was protonated at such a low $\mathrm{pH}$ and thus had a low solubility, leading to a slower diffusion rate. Additionally, IP drug molecules would diffuse more slowly at lower temperatures as governed by thermodynamics. Notably, the relative large standard deviation bar may be due to the bundling of these MFs, which can affect the diffusion rates. But the trend remains the same for all measurements.

\section{Conclusion}

Two types of polymeric microfibers with dramatically different drug release behaviors were fabricated using a simple electrospinning method. It was found that both $\mathrm{pH}$ and temperature have negligible effects on the IP diffusion rates from PCL/IP MFs. In dark contrast, the ibuprofen release rates from pNIPAM-co-MAA MFs are highly controllable with minimum burst effect, owing to the synergetic effects of both $\mathrm{pH}$ and temperature. Ibuprofen release rates from pNIPAM-co-MAA MFs are also highly switchable; that is, the release rate of IP at $22^{\circ} \mathrm{C}$ was $\sim 10$ times faster than that at $40^{\circ} \mathrm{C}$. Such a unique controllable drug delivery system has many potential applications in biomedical and pharmaceutical sciences with a highly efficient treatment efficacy.

\section{Conflict of Interests}

The authors declare that there is no conflict of interests regarding the publication of this paper.

\section{Authors' Contribution}

Toan Tran, Mariana Hernandez, and Dhruvil Patel contribute equally to this work.

\section{Acknowledgments}

The financial support provided by the Georgia Southern University is sincerely acknowledged by Ji Wu, Mariana Hernandez, Toan Tran, and Dhruvil Patel. The authors also deeply appreciate the Department of Chemistry at GSU for infrastructure supports. Toan Tran and Mariana Hernandez sincerely acknowledge the financial support from GSU COUR Award. 


\section{References}

[1] R. Langer, "Drug delivery and targeting," Nature, vol. 392, no. 6679, pp. 5-10, 1998.

[2] T. Bussemer, I. Otto, and R. Bodmeier, "Pulsatile drug-delivery systems," Critical Reviews in Therapeutic Drug Carrier Systems, vol. 18, no. 5, 26 pages, 2001.

[3] T. M. Allen and P. R. Cullis, "Drug delivery systems: entering the mainstream," Science, vol. 303, no. 5665, pp. 1818-1822, 2004.

[4] W. M. Saltzman and W. L. Olbricht, "Building drug delivery into tissue engineering," Nature Reviews Drug Discovery, vol. 1, no. 3, pp. 177-186, 2002.

[5] T. J. Sill and H. A. von Recum, "Electrospinning: applications in drug delivery and tissue engineering," Biomaterials, vol. 29, no. 13, pp. 1989-2006, 2008.

[6] D. A. LaVan, T. McGuire, and R. Langer, "Small-scale systems for in vivo drug delivery," Nature Biotechnology, vol. 21, no. 10, pp. 1184-1191, 2003.

[7] J. Wu, K. S. Paudel, C. Strasinger, D. Hammell, A. L. Stinchcomb, and B. J. Hinds, "Programmable transdermal drug delivery of nicotine using carbon nanotube membranes," Proceedings of the National Academy of Sciences of the United States of America, vol. 107, no. 26, pp. 11698-11702, 2010.

[8] O. C. Farokhzad and R. Langer, "Impact of nanotechnology on drug delivery," ACS Nano, vol. 3, no. 1, pp. 16-20, 2009.

[9] K. Park, "Nanotechnology: what it can do for drug delivery," Journal of Controlled Release, vol. 120, no. 1-2, pp. 1-3, 2007.

[10] S. S. Suri, H. Fenniri, and B. Singh, "Nanotechnology-based drug delivery systems," Journal of Occupational Medicine and Toxicology, vol. 2, no. 1, article 16, 2007.

[11] C. Strasinger, K. S. Paudel, J. Wu et al., "Programmable transdermal clonidine delivery through voltage-gated carbon nanotube membranes," Journal of Pharmaceutical Sciences, vol. 103, no. 6, pp. 1829-1838, 2014.

[12] K. S. Paudel, J. Wu, B. J. Hinds, and A. L. Stinchcomb, "Programmable transdermal delivery of nicotine in hairless guinea pigs using carbon nanotube membrane pumps," Journal of Pharmaceutical Sciences, vol. 101, no. 10, pp. 3823-3832, 2012.

[13] Y. Li, L.-T. Lim, and Y. Kakuda, "Electrospun zein fibers as carriers to stabilize (-)-epigallocatechin gallate," Journal of Food Science, vol. 74, no. 3, pp. C233-C240, 2009.

[14] T. Kiatyongchai, S. Wongsasulak, and T. Yoovidhya, "Coaxial electrospinning and release characteristics of cellulose acetategelatin blend encapsulating a model drug," Journal of Applied Polymer Science, vol. 131, no. 8, Article ID 40167, 2014.

[15] S. Sakuldao, T. Yoovidhya, and S. Wongsasulak, "Coaxial electrospinning and sustained release properties of gelatin-cellulose acetate core-shell ultrafine fibres," ScienceAsia, vol. 37, no. 4, pp. 335-343, 2011.

[16] M. Constantin, S. Bucatariu, V. Harabagiu, I. Popescu, P. Ascenzi, and G. Fundueanu, "Poly $(N$-isopropylacrylamideco-methacrylic acid) $\mathrm{pH} /$ thermo-responsive porous hydrogels as self-regulated drug delivery system," European Journal of Pharmaceutical Sciences, vol. 62, pp. 86-95, 2014.

[17] Y. Sharma, A. Tiwari, S. Hattori et al., "Fabrication of conducting electrospun nanofibers scaffold for three-dimensional cells culture," International Journal of Biological Macromolecules, vol. 51, no. 4, pp. 627-631, 2012.

[18] Y. Qiu and K. Park, "Environment-sensitive hydrogels for drug delivery," Advanced Drug Delivery Reviews, vol. 53, no. 3, pp. 321-339, 2001.
[19] B. S. Forney, C. Baguenard, and C. Allan Guymon, "Improved stimuli-response and mechanical properties of nanostructured poly( $\mathrm{N}$-isopropylacrylamide-co-dimethylsiloxane) hydrogels generated through photopolymerization in lyotropic liquid crystal templates," Soft Matter, vol. 9, no. 31, pp. 7458-7467, 2013.

[20] P. Tian, Q. Wu, and K. Lian, "Preparation of temperature- and $\mathrm{pH}$-sensitive, stimuli-responsive poly $(\mathrm{N}$-isopropylacrylamideco-methacrylic acid) nanoparticles," Journal of Applied Polymer Science, vol. 108, no. 4, pp. 2226-2232, 2008.

[21] J. C. Garbern, A. S. Hoffman, and P. S. Stayton, "Injectable $\mathrm{pH}$ - and temperature-responsive poly $(\mathrm{N}$-isopropylacrylamideco-propylacrylic acid) copolymers for delivery of angiogenic growth factors," Biomacromolecules, vol. 11, no. 7, pp. 1833-1839, 2010.

[22] A. Barhoumi, W. Wang, D. Zurakowski, R. S. Langer, and D. S. Kohane, "Photothermally targeted thermosensitive polymermasked nanoparticles," Nano Letters, vol. 14, no. 7, pp. 36973701, 2014.

[23] A. F. Azarbayjani, J. R. Venugopal, S. Ramakrishna, P. F. C. Lim, Y. W. Chan, and S. Y. Chan, "Smart polymeric nanofibers for topical delivery of levothyroxine," Journal of Pharmacy and Pharmaceutical Sciences, vol. 13, no. 3, pp. 400-410, 2010.

[24] T. Grafe and K. Graham, "Polymeric nanofibers and nanofiber webs: a new class of nonwovens. Nonwoven technology review," International Nonwovens Journal, vol. 12, no. 1, pp. 51-55, 2003.

[25] A. Elzubair, C. N. Elias, J. C. M. Suarez, H. P. Lopes, and M. V. B. Vieira, "The physical characterization of a thermoplastic polymer for endodontic obturation," Journal of Dentistry, vol. 34, no. 10, pp. 784-789, 2006.

[26] S. Garrigues, M. Gallignani, and M. de la Guardia, "FIA-FT-IR determination of ibuprofen in pharmaceuticals," Talanta, vol. 40, no. 1, pp. 89-93, 1993.

[27] D. Li, X. Zhang, J. Yao, G. P. Simon, and H. Wang, "Stimuliresponsive polymer hydrogels as a new class of draw agent for forward osmosis desalination," Chemical Communications, vol. 47, no. 6, pp. 1710-1712, 2011.

[28] D.-Q. Wu, F. Qiu, T. Wang, X.-J. Jiang, X.-Z. Zhang, and R.-X. Zhuo, "Toward the development of partially biodegradable and injectable thermoresponsive hydrogels for potential biomedical applications," ACS Applied Materials \& Interfaces, vol. 1, no. 2, pp. 319-327, 2009. 

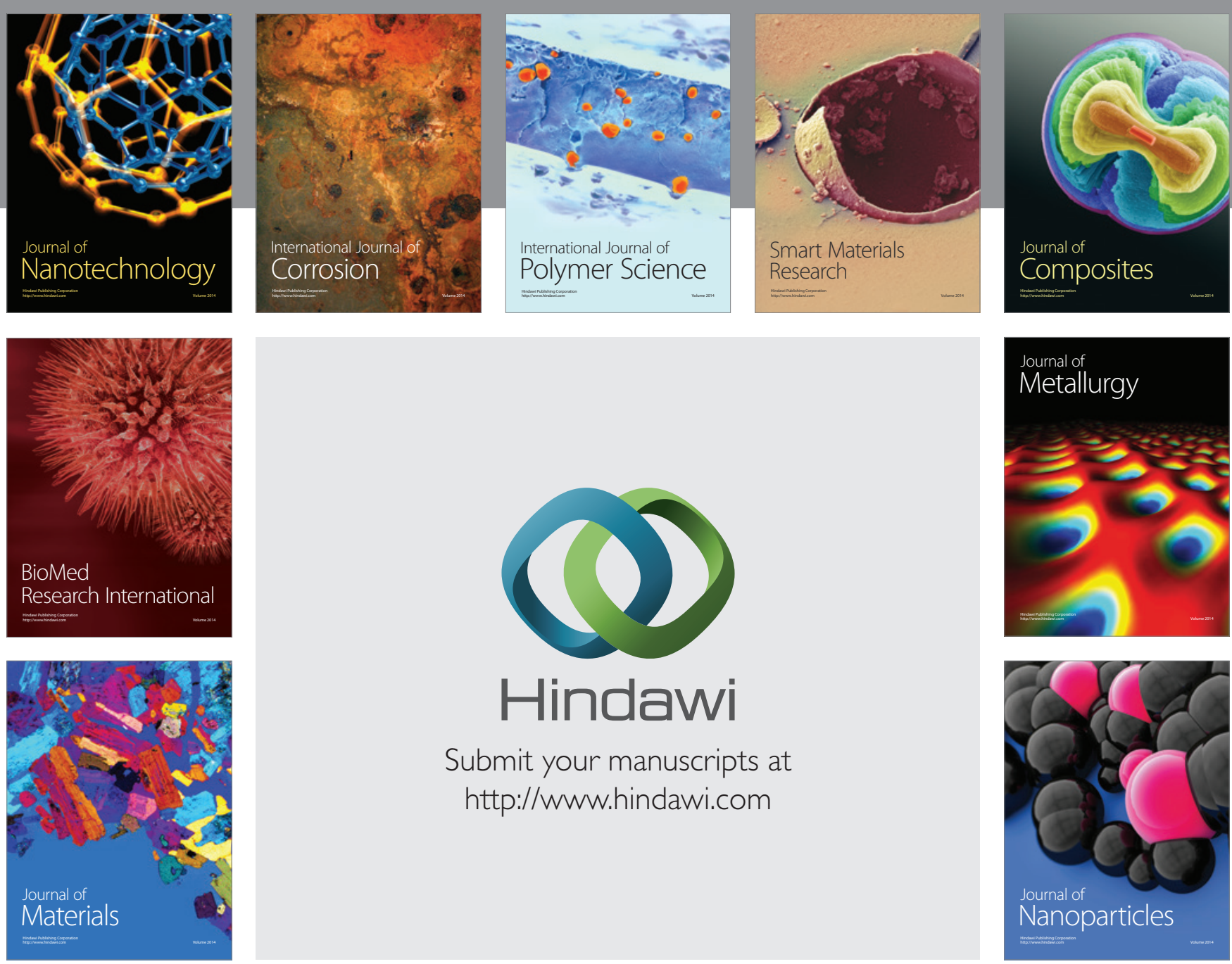

Submit your manuscripts at http://www.hindawi.com
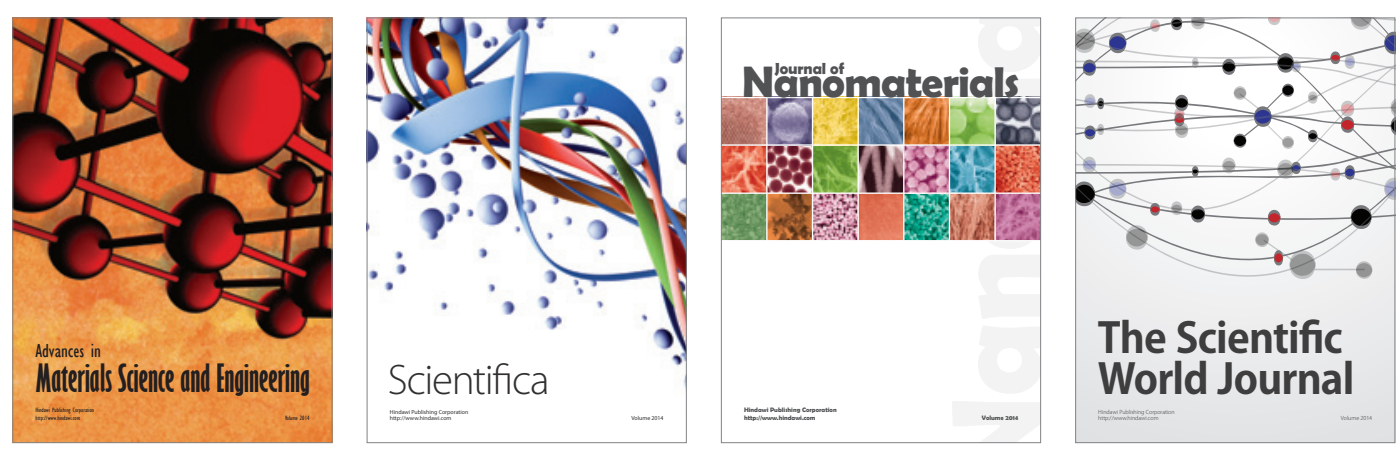

\section{The Scientific World Journal}
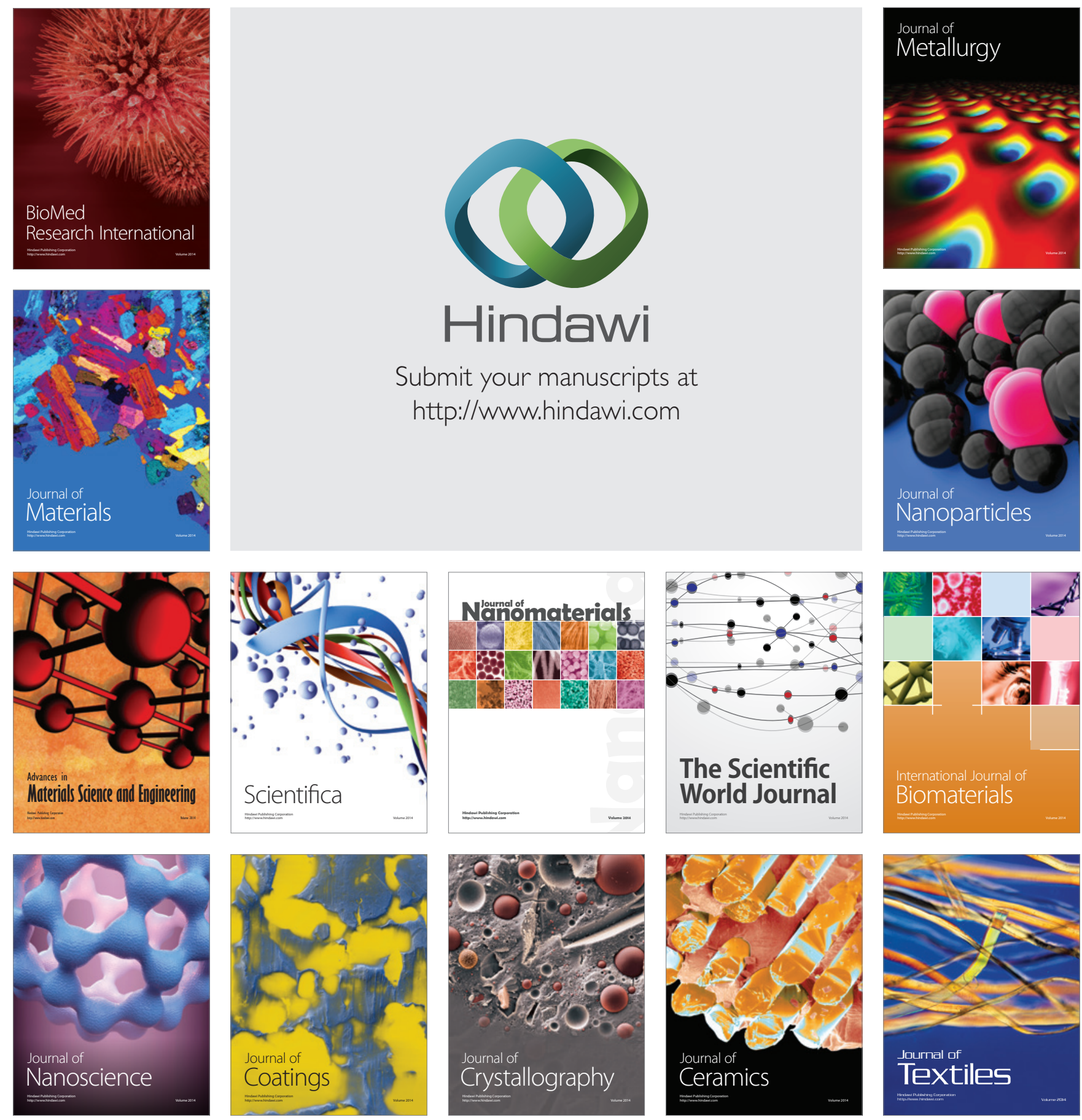